\title{
EFEITO DE DIFERENTES MEIOS DE SUPORTE NA PRODUÇÃO DE HIDROGÊNIO A PARTIR DO TRATAMENTO DE ÁGUAS RESIDUAIS INDUSTRIAIS NÃO ALCOOLICAS
}

\author{
A.C.G GARCIA ${ }^{2}$, A.C.B. MUÑOZ ${ }^{2}$, R. C. ABRA $\mathrm{AO}^{1}$ e A. T. R. CHAPARRO ${ }^{2}$ \\ ${ }^{1}$ Universidade Federal do Rio Grande do Norte, Departamento de Engenharia Química \\ ${ }^{2}$ Universidad Militar Nueva Granada, Laboratório de Saneamiento Ambiental \\ E-mail para contato: adela.rodriguez@unimilitar.edu.co; abraao.ricardoeng@gmail.com
}

\begin{abstract}
RESUMO - Este trabalho tem como objetivo analisar a influência do carvão ativado e do pneu triturado como material suporte na produção de hidrogênio utilizando águas residuais industriais de bebidas não alcoólicas, bem como a determinação do tipo de escoamento nos dois reatores. O experimento foi desenvolvido em dois reatores anaeróbios de fluxo ascendente utilizando um afluente sintético e Clostridium como microorganismo fermentador para a degradação da matéria orgânica. A análise estatística utilizado foi o teste de Tukey com um nível de significância de $p<0.05$. Os materiais empregados como meios de suporte não exerceram influência significativa no rendimento da produção de hidrogênio e os reatores R1 e R2 apresentaram um fluxo pistonado com grande dispersão.
\end{abstract}

\section{INTRODUÇÃO}

O uso de resíduos orgânicos e as águas residuais com alto teor de carga orgânica para a produção de energia por rotas biológicas é uma alternativa de tratamento de efluentes gerando subprodutos como o hidrogênio, dióxido de carbono e metano que se caracterizam como uma fonte renovável de energia. . O hidrogênio que é uma fonte intermediária de energia que pode ser usado para gerar eletricidade através de células a combustível; detém a maior quantidade de energia por unidade de massa do que qualquer outra substância conhecida $(121.000 \mathrm{~kJ} / \mathrm{kg})$ e seu alto rendimento energético é 2,75 vezes superior quando comparado aos combustíveis de hidrocarbonetos (Longo et al., 2008; Cui et al., 2009; Authayanun et al., 2010; Alves, et al., 2013).

Os métodos convencionais para o tratamento de águas residuais do tipo industrial e doméstica tem a desvantagem do alto custo de investimento e as dificuldades de manutenção (Suematsu, 1995). O tratamento por meio de reatores anaeróbios de fluxo ascendente é utilizado principalmente para a degradação de açúcares, tipo de composto característico das águas residuais da indústria de bebidas e tem se tornado um método muito atrativo já que seu consumo de energia é menor e apresenta também baixos custos de implantação, manutenção e operação. 
Esse tratamento pode ser afetado pelo material utilizado como meio de suporte e também pela hidrodinâmica do sistema, causando perdas de eficiência e durabilidade do processo. Dessa forma é necessário pesquisar o efeito da variação de diferentes tipos de materiais suporte e dos regimes hidráulicos nesse processo de forma a avaliar sua eficiência quanto ao tratamento de águas contaminantes. Nesse contexto esse trabalho tem o objetivo de determinar o tipo de escoamento e avaliar a influencia do carvão ativado e do pneu triturado como meios de suporte no rendimento da produção de hidrogênio a partir do tratamento de águas residuais industriais não alcoólicas em reatores anaeróbios de fluxo ascendentes.

\section{MATERIAIS E MÉTODOS}

Foram operados dois reatores anaeróbios de leito fixo e fluxo ascendente cada um com uma capacidade total de aproximadamente $2.6 \mathrm{~L}$. Na figura 01 encontra-se o esquema de montagem.

Figura 01: esquema de montagem dos reatores

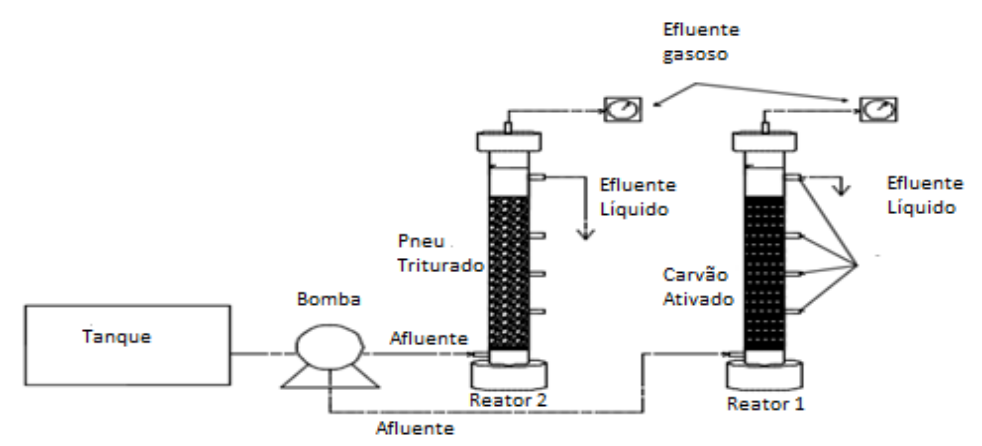

Carvão ativado e pneu triturado foram empregados como meio de suporte nos reatores. Adicionou-se $1640.76 \mathrm{~g}$ de carvão ativado no reator R1 e $1093 \mathrm{~g}$ de pneu triturado no reator R2. A água sintética utilizada como afluente foi preparada de acordo com as características químicas e bioquímicas encontradas em pesquisas relacionadas com o uso de águas residuais das indústrias de refrigerantes segundo Carminato (2013).

Para a inoculação preparou-se a água sintética e deixou em repouso durante 3 dias dentro do reator utilizando o Clostridium como microrganismo fermentador. Em seguida recirculou-se a água no reator durante 5 dias a uma temperatura média de $35^{\circ} \mathrm{C}$. O afluente apresentava um $\mathrm{pH}$ de 5.5 operando sempre a uma temperatura média de $35^{\circ} \mathrm{C}$. (Leite et al. 2008). Utilizou-se cromatografia gasosa para quantificar a composição do biogás produzido por meio do equipamento Agilent 7890A.

A produção de hidrogênio em cada um dos reatores foi submetida a um estudo de ANOVA de modo a avaliar a influencia do material utilizando teste de Tukey com um nível de significância de $p<0.05$, implementado no software Origin Pro.

Nos ensaios de estímulo-resposta tipo pulso foi utilizado o azul de metileno como traçador para o R2 e o cloreto de sódio para o R1, seguindo a metodologia de Levenspiel (2000). O tempo total de duração de cada ensaio foi de 3 vezes o TDH teórico, 2 horas, a uma vazão de 9,2 $\mathrm{ml} / \mathrm{min}$ em $\mathrm{R} 1$ e $12,2 \mathrm{ml} / \mathrm{min}$ em $\mathrm{R} 2$, coletando amostras do efluente em 
intervalos de $20 \mathrm{~min}$. As amostras do R2 foram centrifugadas por aproximadamente 3 min a $3500 \mathrm{rpm}$,em seguida foram determinadas as absorbâncias por meio do método colorimétrico de leitura de absorbância, submetido em um espectrofotômetro HACH UV-VIS modelo $\mathrm{DR} / 5000$, utilizando o comprimento de onda de $665 \mathrm{~nm}$.

As concentrações foram determinadas por meio de uma curva padrão que relacionava concentração e absorbância determinada anteriormente. As amostras coletadas no R1 foram submetidas à eletrólise para determinar a condutividade elétrica e posteriormente encontrar as concentrações das amostras coletadas com o auxilio de uma curva padrão também determinada anteriormente. Os resultados obtidos foram ajustados aos modelos teóricos uniparamétricos de dispersão de pequena intensidade (PD), de grande intensidade (GD) e de tanques de mistura completa em série (N-CSTR) conforme descrito nas tabelas 01 e 02.

Tabela 01: Equações para o cálculo das variáveis hidrodinâmicas

\begin{tabular}{cc}
\hline Variável & Definição da variável (Equação) \\
\hline$E_{i}$ & $\frac{\mathrm{c}_{\mathrm{i}}}{\mathrm{s}}$ \\
\hline$s$ & $\sum \frac{\sum \mathrm{c}_{\mathrm{i}} \cdot \Delta \mathrm{t}_{\mathrm{i}}}{\sum \mathrm{c}_{\mathrm{i}} \cdot \mathrm{t}_{\mathrm{i}} \cdot \Delta \mathrm{t}_{\mathrm{i}}}$ \\
\hline$t_{R}$ & $\frac{t}{t_{r}}$ \\
\hline$\theta$ & $\frac{\sum \mathrm{t}_{\mathrm{i}}^{2} \cdot \mathrm{c}_{\mathrm{i}} \cdot \Delta \mathrm{t}_{\mathrm{i}}}{\sum \mathrm{c}_{\mathrm{i}} \cdot \Delta \mathrm{t}_{\mathrm{i}}}-\mathrm{t}_{\mathrm{r}}^{2}$ \\
\hline$E_{\theta}$ & $\frac{\sigma^{2}}{\mathrm{t}_{\mathrm{r}}^{2}}$ \\
\hline$\sigma^{2}$ &
\end{tabular}

Fonte: Adaptado de Levenspiel (2000).

Tabela 02: Modelos teóricos uniparamétricos de dispersão.

\begin{tabular}{|c|c|c|}
\hline Modelo & Parâmetro & Equação \\
\hline $\begin{array}{l}\text { Dispersão de pequena } \\
\text { intensidade (PD) }\end{array}$ & $\sigma_{\theta}^{2}=2\left(\frac{\mathrm{D}}{\mathrm{u} . \mathrm{L}}\right)$ & $E_{\theta}=\frac{1}{2 \sqrt{\pi\left(\frac{D}{u . L}\right)}} \exp \left[-\frac{(1-\theta)^{2}}{4\left(\frac{D}{u . L}\right)}\right]$ \\
\hline $\begin{array}{l}\text { Dispersão de grande intensidade } \\
\text { (tanque aberto) (GD) }\end{array}$ & $\sigma_{\theta, \mathrm{ta}}^{2}=2\left(\frac{\mathrm{D}}{\mathrm{u} . \mathrm{L}}\right)+8\left(\frac{\mathrm{D}}{\mathrm{u} . \mathrm{L}}\right)^{2}$ & $\mathrm{E}_{\theta, \mathrm{ta}}=\frac{1}{2 \sqrt{\pi\left(\frac{\mathrm{D}}{\mathrm{u} . \mathrm{L}}\right)}} \exp \left[-\frac{(1-\theta)^{2}}{4 \theta\left(\frac{\mathrm{D}}{\mathrm{u} . \mathrm{L}}\right)}\right]$ \\
\hline $\begin{array}{l}\text { Tanques de mistura completa } \\
\text { em série (N-CSTR) }\end{array}$ & $\mathrm{N}=\frac{1}{\sigma_{\theta}^{2}}=\frac{\bar{\theta}_{\mathrm{h}}^{2}}{\sigma^{2}}$ & $E_{\theta}=\frac{N(N \cdot \theta)^{N-1}}{(N-1) !} e^{-N \cdot \theta}$ \\
\hline
\end{tabular}

Fonte: adaptado de Levenspiel (2000). 


\section{RESULTADOS E DISCUSSÃO}

A figura 02 demonstra a variação temporal da produção de hidrogênio nos dois reatores. Durante os primeiros dias de operação a produção de $\mathrm{H}_{2}$ aumentou significativamente em ambos os reatores, no reator R1 variando de 0 até $51 \%$ e no reator R2 de 0 a $70 \%$, depois de atingir esse pico inicia-se uma fase de declínio na produção de $\mathrm{H}_{2}$. Esse comportamento é muito característico dessa etapa inicial segundo informações da literatura. Passada essa etapa inicial verificou-se uma queda abrupta na produção de hidrogênio, durante essa queda também foi identificada um aumento da concentração de $\mathrm{CO}_{2}$ na amostra de biogás. Depois de 33 dias de operação, notou-se uma leve estabilidade na produção de hidrogênio em ambos os reatores, obtendo-se valores de $27 \%$ de $\mathrm{H}_{2}$ nas amostras de biogás, logo depois que a produção de hidrogênio foi decaindo.

Ao comparar os valores de produção de $\mathrm{H}_{2}$ nos reatores pode-se evidenciar que a produção no reator R2 teve um decaimento mais lento e o reator R1 apresentou uma maior repetitividade dos valores medidos, no decorrer dos dias se conseguia obter valores similares em pelo menos 3 medições seguidas, ao contrário do reator R2 onde geralmente seguiam acréscimos e decréscimos consecutivos.

A produção de $\mathrm{H}_{2}$ no reator $\mathrm{R} 1$, utilizando carvão ativado, foi de $32 \%$, enquanto que no reator R2, utilizando pneu triturado, foi de 34\%. Lin e Chang (2004) obtiveram uma produção de aproximadamente $40 \%$ de $\mathrm{H}_{2}$ operando em condições semelhantes, já Fontes et al.(2013) comparou a produção de hidrogênio a partir de glicose e sacarose, obtendo uma produção máxima de hidrogênio de $70,31 \%$ nos primeiros dias de operação, valor muito similar ao encontrado para o reator R2.

Figura 02: Comparação da produção de hidrogênio nos reatores R1 e R2

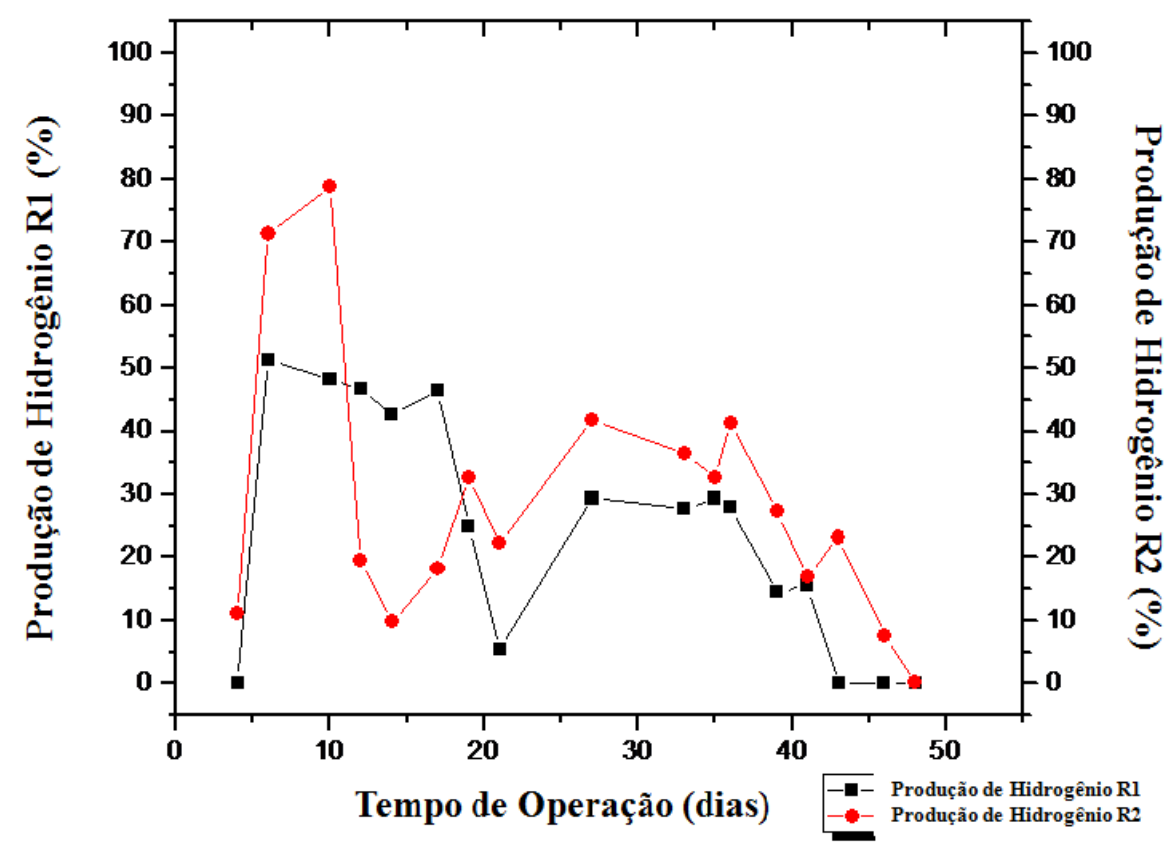


Ao comparar as produções de $\mathrm{H}_{2}$ em R1 e R2 pelo método de Tukey obteve-se o valor estatístico $\mathrm{F}=0,49<\mathrm{F}$ crítico $=4,15$, evidenciando, com uma confiança de $95 \%$, que a diferença do material empregado como meio de suporte nos reatores não influencia significativamente na produção de hidrogênio.

Na tabela 03 são apresentados os coeficientes de correlação ajustados aos modelos matemáticos teóricos. Segundo Levenspiel (2000), a identificação de parâmetros tendendo a zero $(\mathrm{D} / \mu \mathrm{L} \rightarrow 0)$ demonstra uma dispersão negligenciável, caracterizando dessa forma um escoamento pistonado, enquanto a identificação de parâmetros tendendo ao ifinito demonstra uma grande dispersão, caracterizando dessa forma um escoamento com mistura perfeita. Levenspiel classifica ainda o fluxo em pistonado com pequena dispersão quando o parâmetro encontrado é menor que 0,01 . ( $\mathrm{D} / \mu \mathrm{L}<0,01)$ e fluxo pistonado com grande dispersão quando o parâmetro encontrado é um pouco maior que $0,01(\mathrm{D} / \mu \mathrm{L}>0,01)$. Dessa forma analizando os dados da tabela 04, pode-se aferir que o fluxo presente nos reatores R1 e R2 é caracterizado com um fluxo pistonado com grande dispersão.

Tabela 03: Resultado para os coeficientes de correlação (parâmetros)

\begin{tabular}{|l|c|c|c|c|}
\hline \multicolumn{1}{|c|}{ Traçador } & Reator & $\begin{array}{c}\text { Pequena dispersão PD } \\
(\mathrm{D} / \mu \mathrm{L})\end{array}$ & $\begin{array}{c}\text { Grande dispersão } \\
\text { GD }(\mathrm{D} / \mu \mathrm{L})\end{array}$ & $\begin{array}{c}\text { N-CSTR } \\
\text { em série }(\mathrm{N})\end{array}$ \\
\hline Cloreto de sódio & $\mathrm{R} 1$ & 0,1799 & 0,1212 & 3 \\
\hline Azul de metileno & $\mathrm{R} 2$ & 0,1245 & 0,0912 & 4 \\
\hline
\end{tabular}

\section{CONCLUSÃO}

Os materiais empregados como meios de suporte, estatisticamente, não exerceram influência significativa no rendimento da produção de hidrogênio. Os reatores R1 e R2 apresentaram fluxo pistonado com grande dispersão.

\section{AGRADECIMENTOS}

Os autores agradecem ao apoio institucional do laboratório de saneamento ambiental da Universidad Militar Nueva Granada e a Universidade Federal do Rio Grande do Norte, bem como ao programa BRACOL.

\section{NOMENCLATURA}

$\mathbf{E}_{\mathbf{i}}=$ Curva de distribuição de idade de saída do traçador; $\mathbf{S}=$ Área sob a curva de concentração (tempo); $\mathbf{t}_{\mathbf{r}}=$ Tempo médio de residência da curva de DTR; $\boldsymbol{\theta}=$ Tempo de residência médio; $\mathbf{E}_{\boldsymbol{\theta}}=$ Função de distribuição do tempo de residência hidráulica; $\boldsymbol{\sigma}^{2}=$ Variância; $\boldsymbol{\sigma}^{\mathbf{2}} \boldsymbol{\theta}=$ Variância (adimensional); $\mathbf{C}_{\mathbf{i}}=$ Concentração do traçador; $\mathbf{t}_{\mathbf{i}}=$ Tempo em cada instante; $(\mathbf{D} / \mathbf{u} . \mathbf{L})=$ Número de dispersão do reator; $\mathbf{N}=$ Número de reatores em série.

\section{REFERENCIAS}

ALVES, H.J.; JUNIOR, C.B.; NIKLEVICZ, R.R.; FRIGO, E.P.; FRIGO, M.S.; COIMBRAARAÚJO, C.H. Overview of hydrogen production technologies from biogas 
and the applications in fuel cells. Inter. J. of Hydrogen Energy, v. 38, p. 5215-5225, 2013.

AUTHAYANUN, S.; ARPORNWICHANOP, A.; PAENGJUNTUEK, W.; ASSABUMRUNGRAT, S. Thermodynamic study of hydrogen production from crude glycerol autothermal reforming for fuel cell applications. Inter. J. of Hydrogen Energy, v. 35, p. 6617- 6623, 2010.

CARMINATO,V.M. (2013). Influência do cálcio na produção biológica de hidrogênio a partir de águas residuárias em biorreatores anaeróbios. Escola de Engenharia de São Carlos, da Universidade de São Paulo.

CUI, Y.; GALVITA, V.; RIHKO-STRUCKMANN, L.; LORENZ, H.; SUNDMACHER, K. Steam reforming of glycerol: The experimental activity of La1-xCexNiO3 catalyst in comparison to the thermodynamic reaction equilibrium. Applied Cat. B: Envir., v. 90, p. 29-37, 2009.

DÍAZ, I. I. (2004). Utilización de biogás para la generación de biogás. Costa Rica: Ambientice.

FONTES LIMA,D.M., Moreira,W.K.,Zaiat,M.(2013).Comparison of the use of sucrose and glucose as substrate for hydrogen production in an upflow anaerobic fixed - bed reactor. International Journal of Hydrogen Energy 38, 15074-15083

LEITE,J.A.C.,FERNANDES,B.S.,POZZI,E.,BARBOSZA,M. $\quad$ y ZAIAT,M.(2008). Application of an anaerobic packed-bed biorreactor for the production of hydrogen and organic acids. International Journal Hydrogen Energy 33,579-86.

LIN,C-Y. y CHANG,R-C.(2004).Fermentative hydrogen production at ambient temperature. International Journal Hydrogen Energy 29,715-20.

LEVENSPIEL, Octave. Engenharia das Reações Químicas. 3 ed. São Paulo: Edgard Blücher Ltda, 2000.

LONGO, M. A. V.; LAZZARIN, N.; MIGUEZ, T. A. Produção biológica de hidrogênio, 34p. Departamento de Engenharia Química e Engenharia de Alimentos da Universidade Federal de Santa Catarina, 2008

SUEMATSU, I. G. (1995). Tratamiento de aguas y selección de tecnologías enfunción del tipo de reuso. 